\title{
NERVE REGENERATION IN CORNEAL GRAFTS IN THE RABBIT*
}

\author{
BY \\ URSULA REXED \\ From the Nobel Institute for Neurophysiology and the Ophthalmology Clinic, \\ Karolinska Institutet, Stockholm, Sweden
}

A GREAT number of histological studies on corneal grafts are to be found in the current literature. In very few of these, however, has any attention been paid to the nerves. Only a few authors have used nerve stainings. The present investigation has been made with the object of seeing whether any defects in the regeneration of the corneal nerves could have to do with the clouding of the grafts. The processes in regeneration of severed corneal nerves have been studied by Rexed and Rexed (1951).

Leoz Ortin (1931) found complete return of sensitivity in his grafts some weeks after operation and he also verified re-innervation at this time histologically.

Babel and Campos (1946) described the re-innervation of four cloudy grafts in homine at ages varying from 36 days to 5 years. They found a few disordered nerves in the grafts but were not able to stain any subepithelial nerve network although this was well developed in the host cornea. Franceschetti and Babel (1947) examined a graft from homo which had been clear for 6 years. They found a welldeveloped subepithelial nerve network which connected with the network in the host cornea. They suggested that there might be some connection between the development of the subepithelial nerves and the transparence of the graft. Babel (1950) has collected his experiences in a monograph on anatomical processes in the healing of corneal grafts. He found that it was at least a month before the graft began to be re-innervated. The regenerated nerve fibres were irregularly spread and accompanied by numerous Schwann cells. This he considered to demonstrate a very lively regeneration. He found a similar distribution of the nerves in clear and in cloudy grafts and only seldom saw the nerves accompanying blood vessels.

Escapini (1948) studied the degeneration and regeneration of the nerves in corneal grafts in rabbits. He also studied degeneration in vitro. He did not manage to elicit a corneal reflex from any of his

- Received for publication September 2, 1950. 
cases till after 45 days nor could he find any nerves in preparations less than 45 days old.

Kornblueth and others (1949) studied the regeneration of nerves in partially penetrating corneal grafts examined after periods of from 2 days to one year. They tested the sensitivity of their grafts with von Frey hairs and examined them histologically after silver impregnation. They had seventeen clear and thirteen cloudy grafts. The return of deep sensitivity in the grafts after 4 to 6 weeks corresponded to the ingrowth of nerves into the midstroma. The acquisition of light sensitivity in 3 to 4 months corresponded to the penetration of nerves into the subepithelial and epithelial regions of the grafts. No appreciable difference was found in the regeneration of nerves into clear and cloudy grafts. The ingrowth of nerve fibres into the grafts was not found to depend upon the invasion of the grafts by blood vessels. A disappearance of the nuclei of the Schwann cells on degeneration of the nerves in the graft is described.

\section{Material AND Methods}

This investigation has been made on corneal grafts in the rabbit. Twenty-three grafts were examined at intervals of from one day to $7 \frac{1}{2}$ months after operation. Eight grafts were completely clear, one was clear over half its extent, four were slightly, and eight completely cloudy. Seven of the rabbits were fully grown adults, the other sixteen were young rabbits about 6 months old (see Table opposite).

The operation was performed in Dial narcosis with the greatest possible degree of sterility. A 4-mm. circular trephine was used. The grafts were anchored with crossed corneal sutures which were cut after 3 to 5 days. The rabbits were given atropine and penicillin locally 3 times daily for the first 14 days and then atropine once daily for 14 days. Cloudy grafts were treated with an ointment of mercuric oxide once daily. The sensitivity of the grafts was tested at short intervals from 14 days after operation.

Sensitivity was tested with von Frey hairs held at right angles to the corneal surface. It was only possible to attain a moderate degree of accuracy in grading the sensitivity of the grafts. The animals are very difficult to test and the corneal reflex is often inhibited through fright. I have therefore merely attempted to register when the graft seemed completely insensitive and when certain areas responded by a reflex to contact with the hair. The eyelashes and whiskers were cut before examination so as to avoid false reflexes.

When the eyes had been enucleated the cornea was cut out. Three radial cuts were made in order to flatten out the preparation. This was fixed in a 10 per cent. solution of neutral formaldehyde to which 1.1 per cent. $\mathrm{NaCl}$ had been added. The cornea was then sectioned in sections 100 micrones thick parallel to the spread-out corneal surface. In this way one obtains circular sections in which individual nerve fibres can be followed over large parts of the cornea. The sections were silver-impregnated according to Gros-Schultzes method, as described in Rexed and Rexed (1951).

\section{RESULTS}

In spite of all possible precautions and careful asepsis it was very difficult to prevent infection in the operated eyes. One could not keep any dressing on the animal and suturing of the eyelids led to 
severe conjunctivitis. However, most of the animals had their eyelids sutured for the first 2 to 3 days, the conjunctival sac being, washed out with sterile saline three times daily. The graft fell out in five of the thirty animals operated on. In two cases a severe deep keratitis developed which made further histological examination meaningless.

TABLE

AGE OF GRAFTS ON REGAINING SENSITIVITY

\begin{tabular}{|c|c|c|c|c|}
\hline \multirow{2}{*}{ Age of Graft } & \multirow{2}{*}{$\begin{array}{l}\text { Degree of } \\
\text { Clearness }\end{array}$} & \multicolumn{3}{|c|}{ Sensitivity Attained (weeks) } \\
\hline & & Parts & Whole slightly & Whole fully \\
\hline $\begin{array}{l}\text { Adult Animals } \\
2 \text { months } \\
5 \frac{1}{2} \text { months } \\
6 \text { months } \\
6 \frac{1}{2} \text { months } \\
\\
6 \frac{1}{2} \text { months } \\
7 \frac{1}{2} \text { months } \\
7 \frac{1}{2} \text { months } \\
\text { Young Animals } \\
11 \text { day } \\
3 \text { days } \\
1 \text { week } \\
2 \text { weeks } \\
2 \text { weeks } \\
3 \text { weeks } \\
3 \text { weeks } \\
4 \text { weeks } \\
4 \text { weeks } \\
4 \text { weeks } \\
4 \text { weeks } \\
5 \frac{1}{2} \text { weeks } \\
6 \text { weeks } \\
5 \frac{1}{2} \text { months } \\
5 \frac{1}{2} \text { months } \\
5 \frac{3}{4} \text { months }\end{array}$ & $\begin{array}{l}\text { - } \\
\text { cloudy } \\
\text { clear } \\
\text { clear } \\
\text { cloudy } \\
\text { cloudy } \\
\text { cloudy } \\
\text { cloudy } \\
\text { cloudy } \\
\text { cloudy } \\
\text { cloudy } \\
\text { clear } \\
\text { clear } \\
\text { cloudy } \\
\text { clear }\end{array}$ & $\begin{array}{l}-\bar{c} \\
\overline{-} \\
- \\
3 \\
3 \\
4 \\
4 \\
3 \\
4 \\
4 \\
4 \\
4 \\
4\end{array}$ & $\begin{array}{l}- \\
E \\
- \\
- \\
- \\
- \\
- \\
\overline{4} \\
4 \\
6 \\
>4 \frac{1}{2} \\
>4 \frac{1}{2} \\
5\end{array}$ & $\begin{array}{c}- \\
>8 \\
>8 \\
\text { centre never fully } \\
\text { sensitive } \\
10 \frac{1}{2} \\
13 \\
13 \\
- \\
- \\
- \\
- \\
- \\
- \\
- \\
- \\
\text { - } \\
\text { centre never fully } \\
\text { sensitive } \\
7\end{array}$ \\
\hline
\end{tabular}

The remaining twenty-three cases are those examined here. In thirteen there was a slight intra-ocular infection, and only one of these grafts became clear. Blood vessels could be seen growing into the cornea in all of them. The remaining eight grafts were clear; these had shown no signs of intra-ocular infection after operation and no blood vessels could be seen in them. These clear grafts did not become clouded during the follow-up period (i.e., up to $7 \frac{1}{2}$ months, see Table). The cloudy grafts became clearer on treatment with mercuric oxide ointment and two of them cleared under this treatment.

The grafts of adult animals were slightly sensitive after 5 to 7 weeks 
and those of younger ones after 4 weeks. In grafts with ingrowth of blood vessels these parts of the grafts were the first to regain sensitivity. The sensitivity of the graft was first comparable to that of the host cornea after 10 to 13 weeks in older animals and 4 to 7 weeks in younger animals.

\section{Histological ObServations}

The scar between the graft and the host cornea was denser than the surrounding tissue. The cells here were tightly packed, often enlongated, and arranged lengthwise. In this way the structure of the scar became circular. Its breadth differed in different cases depending on how exactly the graft had healed in. The stroma cells of the graft were usually more irregularly arranged than those of the host. However, with time this difference became less marked.

The severed nerve fibres of the host cornea could often be seen very clearly outside the scar. In no preparation could any reaction from the Schwann cells be seen, and a growing out of these towards the scar was never observed. Nor was there any reaction from the Schwann cells in the graft. This absence of reaction on the part of the Schwann cells is in accordance with what has been seen in simple severance of the corneal nerves (Rexed and Rexed, 1951).

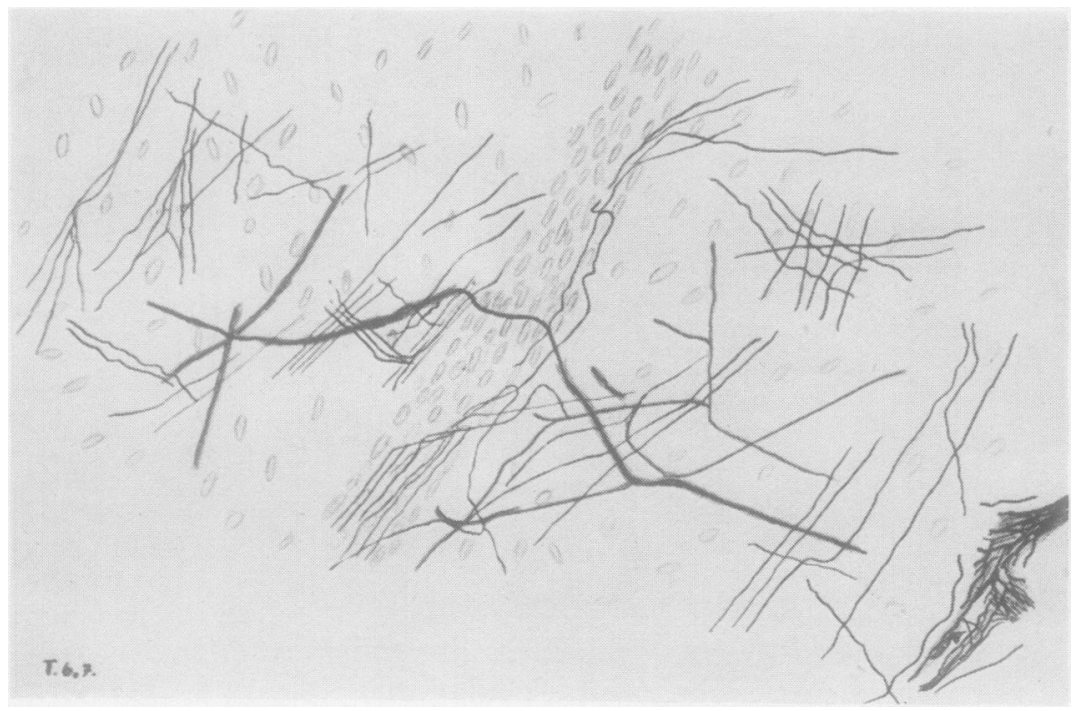

Fig. 1.-Numerous new neurites outside and inside the scar. Most of the neurites are naked while a few are sheathed. Six and a half months after operation. Low magnification.

The severed nerve fibres in the host cornea do not degenerate for more than $1-2 \mathrm{~mm}$. in the retrograde direction. The new neurites grow out from them, partly from their end, and partly from as far as $2 \mathrm{~mm}$. further back in the form of side branches. Already after 3 to 4 weeks one can see a great number of proliferating new neurites growing in the direction of the graft. Just outside and in the scar these neurites often grow in a circular direction for a certain distance (Fig. 1) before turning inwards towards the graft. Apparently the neurites follow supporting structures, in this case the circularly arranged corneal cells in the scar tissue. 
The new neurites growing towards the scar are always naked and grow without the support of Schwann cells. This is the case even in the scar, where they often follow a very irregular and sinuous course. Once they have managed to penetrate the scar and to enter the graft their course is straighter and more regular. The neurites branch to a certain degree just inside as well as outside the scar so that a network of fibres is formed in the outer parts of the graft.

The nerve fibres in the graft degenerate completely and no remnants of them were found later than seven days after the operation. The Schwann sheaths are left, however, and can be seen in all preparations (Figs 2-4). There is no reaction on the

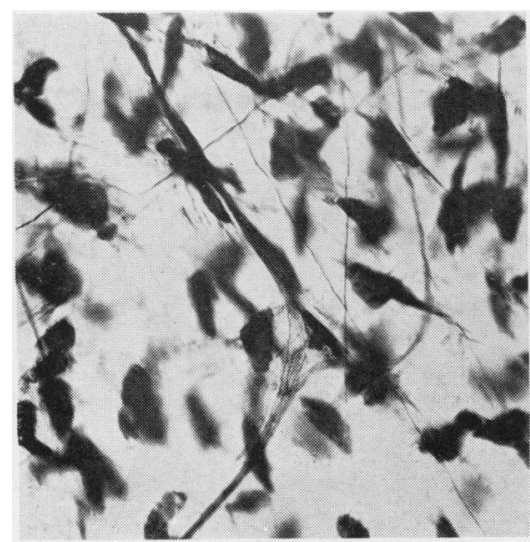

FIG. 2.-Partly re-innervated Schwann sheath surrounded by naked neurites. Six and a half months after operation. High magnification.

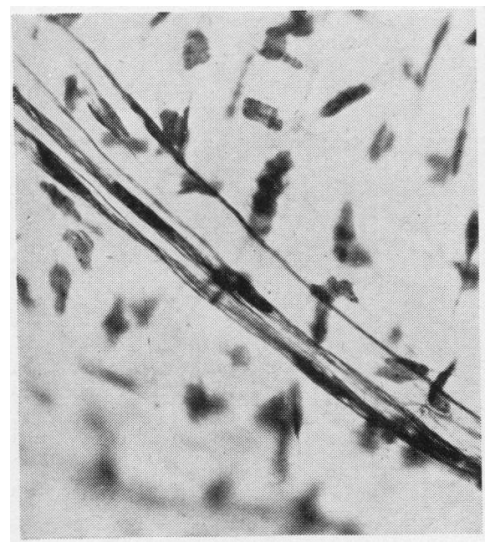

Fig. 4.-Re-innervated and empty Schwann sheaths side by side. Six and a half months after operation. High magnification.

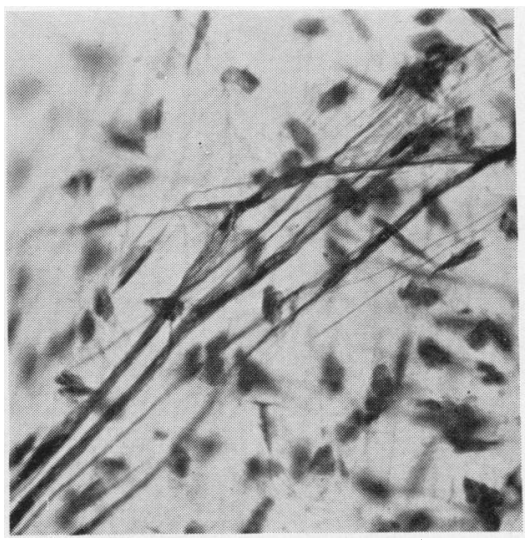

Fig. 3.-Empty and partly re-innervated Schwann sheaths side by side with naked neurites. Six and a half months after operation. High magnification. 
part of the Schwann cells or sheaths in the host cornea or in the graft and no mitoses have been seen in them. Since no Schwann cells have grown into the graft from the host cornea, the empty sheaths cannot be newly formed and so at least some parts of the original graft must still remain $7 \frac{1}{2}$ months after operation.

The new neurites either grow directly towards the centre of the graft or first circle in the scar for a short distance and then bend inwards to the centre. Many enter empty Schwann sheaths and re-innervate them. Others do not find any sheaths and continue their course naked towards the centre of the graft. It is common in preparations to find naked neurites and re-innervated Schwann sheaths side by side (Figs 3 and 4). All Schwann sheaths do not become re-innervated and empty sheaths can be seen even in the oldest preparations (Fig. 2).

The re-innervation of the graft results in an excess of nerve fibres. In comparison with a piece of normal central cornea of the same area as the graft, the latter has many more nerve fibres. Many of these are without sheaths. Of theoretical interest are the facts that most of the unsheathed fibres that have arrived at the centre of the graft remain naked (see Fig. 5) and that they even mature, increase their calibre, and must be considered to take up function. This shows that even neurites in the peripheral nervous system can grow and function without the presence of Schwann sheaths.

In grafts of 3 to 5 weeks of age there are many new neurites just outside the scar but only a few have started to penetrate it and grow into the graft. After 6 to 8 weeks one finds a great number of new neurites already inside the scar, but the inner parts of the graft have not yet as many fibres as the outer. After 3 to $7 \frac{1}{2}$ months one finds a great number of fibres in the whole graft and these are so mature that both fine and coarse fibres are seen in the re-innervated nerve truncs.

Subepithelial nerve fibres are seen at the earliest in preparations five weeks after transplantation. In older cases they become more and more numerous and in cases from 5 to 7 months after operation the whole subepithelial network is well developed. The deepest parts of the cornea show no ingrowth of nerve fibres and become, as in normal cornea, void of nerves.

Only in a few preparations where there is abundant ingrowth of blood vessels can the ingrowing nerves be seen to follow them.

The degeneration and regeneration of the nerves follow the same pattern in clear and in cloudy grafts.

\section{Discussion}

The course and pattern of nerve regeneration in corneal grafts is similar in principle to that which occurs after simple severance of the corneal nerves by means of incisions of the cornea down to Descemet's membrane (Rexed and Rexed, 1951). There are, however, certain differences. In both cases one finds a profuse proliferation of naked neurites outside and even inside the scar. After severance of the nerves in the periphery of the cornea one finds these neurites outside and inside the scar, but in the central parts of the cornea only sheathed fibres are seen. In the grafts, there is a mass of naked neurites in the centre, the nerves being much more abundant here than in normal corneal tissue. These naked neurites mature and grow even outside the Schwann sheaths, the presence of which has previously been considered necessary for these processes. Judging 
from the well developed sensitivity of the grafts these naked neurites probably also function. Possibly it is the shorter distance which makes it possible for unsheathed neurites to reach the centre of the graft while neurites cut peripherally in the cornea only reach the centre when sheathed.

One can see many Schwann sheaths even in grafts of 5 to $7 \frac{1}{2}$ months of age. Since there has been no proliferation and no ingrowth of Schwann cells, no new sheaths can have been formed. Therefore, those seen in the graft must be the original ones. This shows that after $7 \frac{1}{2}$ months there must still remain at least parts of the original graft.

Escapini (1948) found remnants of degenerated nerves in 30-day-old grafts. In the present investigation no such remnants were seen in preparations more than a week old. This is in accord with the results found on simple severance of corneal nerves (Rexed and Rexed, 1951), when no degeneration products were found later than 5 to 7 days after operation. He did not find any new nerve fibres in the grafts until after 45 days. This is in accord with my results for adult animals. In young animals I could elicit a corneal reflex after 4 weeks and found nerve fibres in some preparations of the same age. It is well known that nerve regeneration takes place at a more rapid rate in young than in adult animals.

Franceschetti and Babel (1947) have suggested that the clouding of corneal grafts might depend in some way on defective regeneration of the subepithelial branches of the corneal nerves. They had found subepithelial fibres in a clear graft, whereas Babel and Campos (1946) had not been able to demonstrate them in four cloudy grafts. It is hard, however, to draw any conclusions from the absence of nerves after silver impregnation, as it is often very difficult to stain finer nerve fibres such as the subepithelial fibres. In my preparations the subepithelial nerve-network has been equally well developed in clear and in cloudy grafts.

The results of Kornblueth and others (1949) as to the time it takes for the graft to be re-innervated are mainly in accordance with the results found in the present investigation. I have, however, not considered it possible to differentiate between superficial and deep sensitivity and so to correlate the former with the development of the subepithelial nerves. The authors mentioned above did not find any difference in the innervation of cloudy and clear grafts, nor did they find the ingrowth of nerve fibres to be dependent on the ingrowth of blood vessels. These results are all the same as found in this investigation. Their description of the process of degeneration and regeneration is not however identical with the course seen in my preparations. They state that the nuclei of the Schwannsheath cells disappeared during degeneration of the nerve fibres. In an earlier investigation (Rexed and Rexed, 1951) where the 
degeneration and regeneration of corneal nerves after severance at the periphery of the cornea has been studied, the whole process in the cornea could be followed with the utmost clarity and was found to differ from that in other peripheral nerves. Here is was possible to demonstrate that, in the case of the corneal nerves there was no reaction whatsoever on the part of the Schwann cells. There was neither proliferation nor degeneration, and empty denervated Schwann sheaths could easily be seen in even the oldest cases, up to $7 \frac{1}{2}$ months after operation. Most of them however became re-innervated by ingrowing neurites. In the corneal grafts studied in the present investigation the Schwann cells behaved in an identical manner. There was neither degeneration nor proliferation of Schwann cells, and Schwann sheaths of perfectly normal structure could be seen in the grafts.

Babel (1950) also observed the presence of Schwann cells in the graft, but considered them to be under proliferation.

The degeneration of Schwann-cell nuclei as described by Kornblueth and others (1949) could take place if the entire graft disintegrated, and all its cells degenerated. However, Maumenee and Kornblueth (1948) have stated that this is not the case.

The clouding of the grafts in my material has always developed after an intra-ocular infection. Several of the grafts have become less cloudy after treatment with mercuric oxide ointment. Secondary clouding of the grafts has not occurred during the time the animals were observed (up to $7 \frac{1}{2}$ months).

\section{SUMMARY}

(1) Nerve degeneration and regeneration has been studied in 23 corneal grafts in rabbit. The return of sensitivity has been followed and silver-impregnated sections have been made after periods of from one day to $7 \frac{1}{2}$ months from operation.

(2) The peripheral parts of the graft became sensitive after 3 to 4 weeks in young animals and after 5 to 7 weeks in adults. Full sensitivity could be demonstrated after 4 to 7 weeks in young and after 10 to 13 weeks in adult animals.

(3) The processes of degeneration were completed and the neurites completely resorbed after 7 days.

(4) After 3 to 5 weeks regenerated nerve fibres had started to cross the scar and grow into the graft. After 6 to 8 weeks numerous nerve fibres were seen in the periphery of the graft and a few even in the centre. After 3 to $7 \frac{1}{2}$ months mature fibres were found throughout the whole of the graft.

(5) No proliferation of the Schwann cells could be demonstrated either in the host cornea or in the graft. The growing neurites were not supported by Schwann cells as they grew through the scar. In 
all preparations empty and partly re-innervated Schwann sheaths could be observed. These must therefore be the original Schwann sheaths that remained after the degeneration of the neurites. This shows that at least after 6 to 7 months parts of the original graft must still remain.

(6) The new neurites grow out in great numbers from the cut end of the nerve in the host cornea and grow naked through the scar. When they have penetrated the graft they either grow into and re-innervate an empty Schwann sheath or grow on naked towards the centre of the graft. The neurites continue to divide and to grow in towards the centre so that here there are more nerve fibres than in a corresponding area of normal cornea. Both naked and sheathed nerve fibres increase in calibre.

(7) Subepithelial nerve fibres could be demonstrated at the earliest after 5 weeks and could be seen both in clear and in cloudy grafts. In grafts with ingrowth of blood vessels the corneal reflex could, in many cases, be elicited earlier from this area than from the rest of the graft. On the other hand histological examination showed that the ingrowth of nerves did not depend upon the ingrowth of blood vessels.

(8) The process of degeneration and regeneration of the corneal nerves was identical in clear and in cloudy grafts.

\section{REFERENCES}

BABEL, J. (1950). " "Les processus anatomiques de cicatrisation des greffes de cornée ". Bibl. Ophtal., Fasc. 35. Karger, Basel.

and CAMPOS, R. (1946). Ophthalmologica, Basel, 111, 140.

EsCAPINI, H. (1948). Arch. Ophthal., Chicago. 39, 135.

Franceschetti, A., and Babel, J. (1947). Ann. Oculist., Paris, 180, 142.

Kornblueth, W., Maumenee, A. E., and Crowell, J. (1949). Amer. J. Ophthal., 32, 651 .

LeOz ORTIN, G. (1931). Med. ibera, 25, 213.

Maumenfe. A. E., and Kornblueth, W. (1948). Amer. J. Ophthal., 31, 1384.

REXED, B., and REXED, U. (1951). British Journal of Ophthalmology, 35, 38. 